\title{
The presence of air pollution particulate matter in cryopreserved placental tissue cells
}

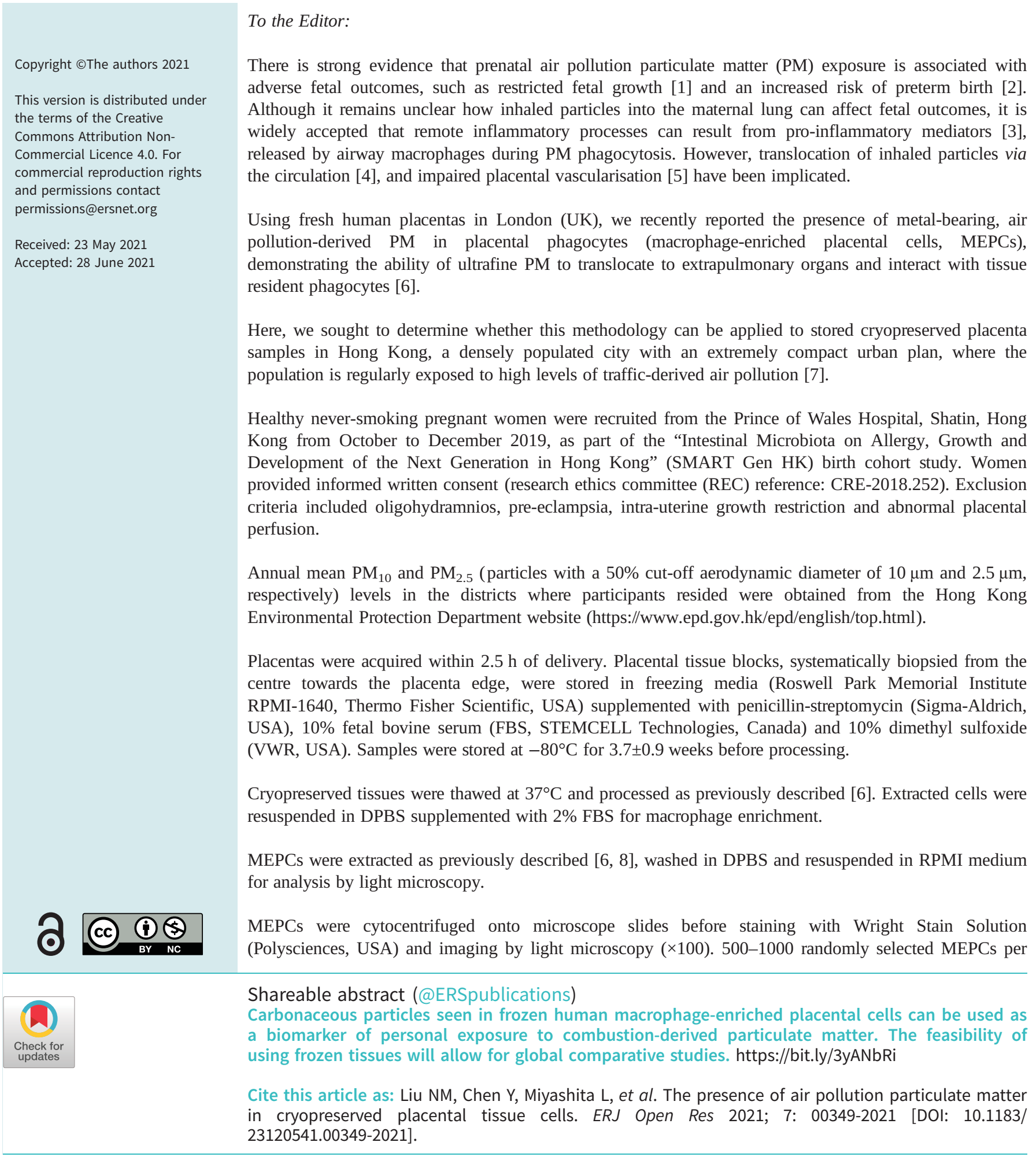


sample were examined, the mean area $\left(\mu \mathrm{m}^{2}\right)$ of black inclusions within each MEPC was quantified using the ImageJ software 1.50i (National Institute of Health, USA) as previously described [9]. Results were compared with the MEPC carbon data from the London cohort [6] (REC-reference: 17/NW/0092).

Data are presented as mean \pm standard error of the mean (SEM) and compared by t-test. Analyses were performed using Prism 8.00 (GraphPad Software, CA, USA). Results are considered significant at $\mathrm{p}<0.05$.

Six healthy never-smoking pregnant women donated their placentas. Subjects resided within $20 \mathrm{~km}$ of the Prince of Wales Hospital, with annual mean $\mathrm{PM}_{10}$ and $\mathrm{PM}_{2.5}$ exposure of $29 \pm 0.63 \mu \mathrm{g} \cdot \mathrm{m}^{-3}$ and $18 \pm 0.63 \mu \mathrm{g} \cdot \mathrm{m}^{-3}$, respectively; all women delivered a healthy singleton infant at term by uncomplicated spontaneous or assisted vaginal delivery.

MEPCs had heterogenous morphology typical of macrophages (figure 1a-d). Black inclusions were observed in MEPCs from all samples and were compatible with the appearance of PM identified in MEPCs from healthy women in London [6]. A minimum threshold of $\geqslant 500$ cells per participant was selected for quantitative analysis. Five of six samples contained $\geqslant 500$ cells. For each sample, 500-1000 cells were randomly selected. Black inclusions were observed in an average of $1 \%$ of MEPCs from all women (mean MEPC carbon $0.0044 \pm 0.0005 \mu \mathrm{m}^{2}$, figure 1e and $\mathrm{f}$ ). The black inclusions were irregularly shaped, compatible with appearance of phagocytosed PM in MEPCs from women in London [6], and airway macrophages from healthy children in London [10, 11], REC-reference: 17/EM/0023, (figure $1 \mathrm{~g}$ and h). Mean MEPC carbon from cryopreserved samples was similar to that previously reported in MEPCs extracted from fresh placentas from women in London $\left(0.0044 \pm 0.0009 \mu \mathrm{m}^{2}, \mathrm{p}=0.97\right.$, figure 1i) [6]. Exposure of London women was similar to that of women from Hong Kong (modelled annual mean $\mathrm{PM}_{10}$ of $27.22 \pm 0.60 \mu \mathrm{g} \cdot \mathrm{m}^{-3}$ in London versus $29.00 \pm 0.63 \mu \mathrm{g} \cdot \mathrm{m}^{-3}$ in Hong Kong, $\mathrm{p}=0.09$; and modelled annual mean $\mathrm{PM}_{2.5}$ of $16.94 \pm 0.38 \mu \mathrm{g} \cdot \mathrm{m}^{-3}$ in London versus $18.00 \pm 0.63 \mu \mathrm{g} \cdot \mathrm{m}^{-3}$ in Hong Kong, $\mathrm{p}=0.15$ ) [6].

We previously showed that MEPCs in extrapulmonary tissues are exposed to, and can interact with, translocated traffic-derived nanoparticles. It remains unclear if the concentration of nanoparticles is sufficient to have adverse effects in these distant sites. However, it is widely accepted that the amount of black carbon in airway macrophages reflects longer term PM exposure [12]. In the present study, we sought to demonstrate the feasibility of using cryopreserved placental samples to extract MEPCs.
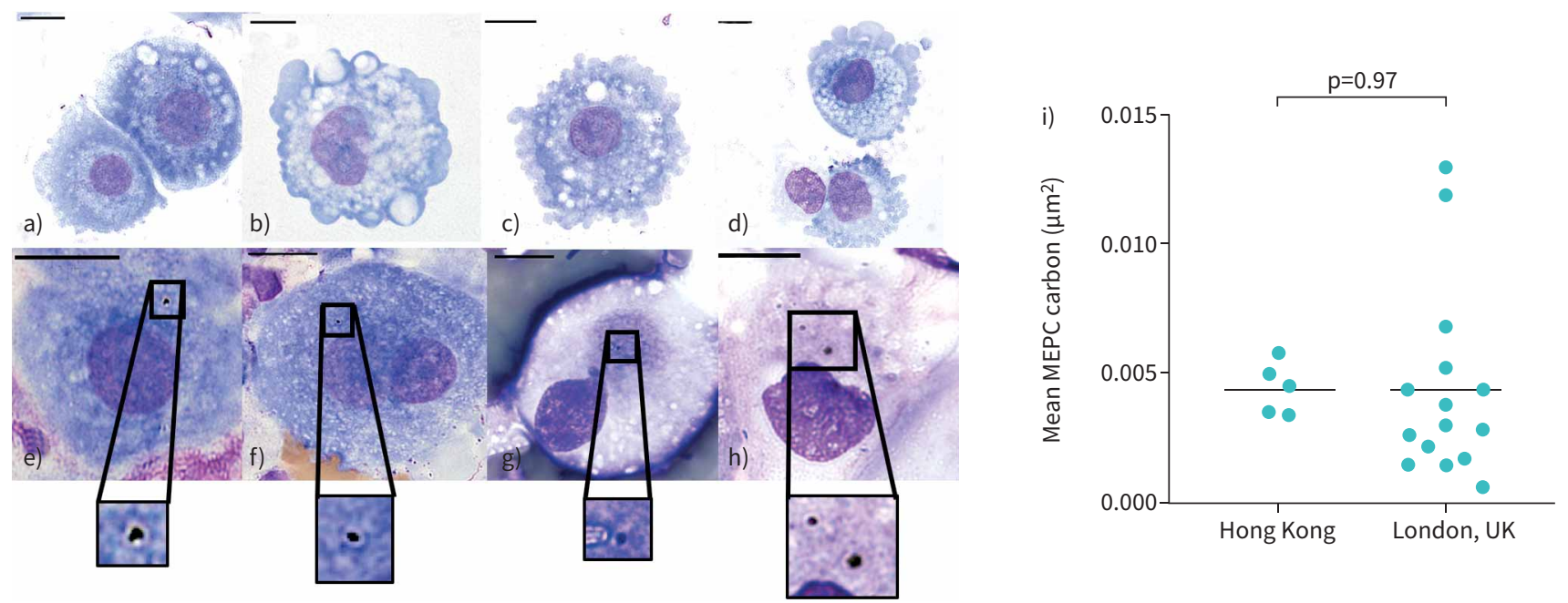

FIGURE 1 a-d) Examples of macrophage-enriched placental cell (MEPC) isolates extracted from cryopreserved placental tissues under light microscopy, their heterogenous morphology (irregular outline, with cytoplasmic vacuolation and lamellipodia) is typical of macrophages. e) and f) Light microscopy images of MEPC isolates from different Hong Kong participants: black inclusions are compatible with those in fresh placental cell isolates previously reported in London, UK (g) [6]. h) Example of phagocytosed particulate matter in an airway macrophage obtained by sputum induction from a healthy child in London [11]. i) Comparison of MEPC carbon from Hong Kong extracted from cryopreserved tissues and London extracted from freshly collected placentas [6]. Mean placental macrophage black carbon was determined from 500 to 1000 cells. Comparison by unpaired t-test. Bars represent mean. Scales bars $=10 \mu \mathrm{m}$. 
Bové et al. [13] reported the presence of black carbon in biobanked placental tissues and demonstrated the feasibility of using stored placental tissues to detect black particles. Here for the first time, also using stored tissues, we identified inclusions of carbonaceous particulate matter in MEPCs from women in Hong Kong. We previously showed that these cells have phagocytic capacity [6]; their interactions with particles may have potential to cause adverse health effects, as seen in the lungs where PM phagocytosis by airway macrophages results in release of inflammatory mediators.

There are limitations to this study. First, we did not test for cell viability post-freezing. However, nonviable cells often have altered morphology and do not survive the enrichment process. Second, the small sample size and absence of personal pollutant exposure data is insufficient to assess the association between MEPC carbon loading and PM exposure.

The advantage of using cryopreserved over fresh placental tissue is that it removes the need to process samples immediately, allowing MEPC carbon loading comparison in samples collected from different areas at different times. Compared with MEPC carbon loading in fresh London samples, MEPC carbon loading in Hong Kong samples was of a similar order of magnitude (mean \pm SEM $0.0044 \pm 0.0005 \mu \mathrm{m}^{2}$ in Hong Kong versus $0.0044 \pm 0.0009 \mu \mathrm{m}^{2}$ in London) [6]. Hong Kong and London have comparable levels of PM, as reported in this study. Indeed, in 2016, the annual mean of $\mathrm{PM}_{2.5}$ was $20 \mu \mathrm{g} \cdot \mathrm{m}^{-3}$ in Shatin, Hong Kong (https://www.epd.gov.hk/epd/english/top.html), and $13.3 \mu \mathrm{g} \cdot \mathrm{m}^{-3}$ in London (https://londonair.org.uk/ LondonAir/Default.aspx).

This study suggests that cryopreserved MEPC carbon loading is a promising biomarker to assess associations between maternal exposure and birth outcomes. This technique is suited to studies in pregnant women exposed to burning of biomass fuels, since in many areas of the world over $90 \%$ of rural homes use biomass as the primary cooking/heating fuel [14]. Furthermore, airway macrophage carbon loading is higher in women exposed to biomass burning compared with those using cleaner cookstoves [15]. Analysis of extracted MEPCs shows the presence of carbonaceous PM with the appearance of fossil-fuel derived PM. We conclude that MEPC carbon loading in cryopreserved placental tissues is a promising biomarker of exposure of pregnant women to combustion-derived PM.

\section{Norrice M. Liư ${ }^{1}$, Yehao Chen $\mathbb{0}^{2}$, Lisa Miyashita ${ }^{1}$, Wing Hung Tam $^{3}$, Noelle A. Ngai ${ }^{4}$, Jonathan Grigg $\oplus^{1}$ and Ting Fan Leung ${ }^{2,5}$}

${ }^{1}$ Centre for Genomics and Child Health, Blizard Institute, Queen Mary University of London, London, UK. ${ }^{2}$ Dept of Paediatrics, The Chinese University of Hong Kong, Prince of Wales Hospital, Hong Kong. ${ }^{3}$ Dept of Obstetrics and Gynaecology, The Chinese University of Hong Kong, Prince of Wales Hospital, Hong Kong. ${ }^{4}$ Dept of Paediatrics, Prince of Wales Hospital, Hong Kong. ${ }^{5}$ Hong Kong Hub of Paediatric Excellence, The Chinese University of Hong Kong, Hong Kong.

Corresponding author: Norrice M. Liu (n.liu@qmul.ac.uk)

Submitted article, peer reviewed.

Author contributions: N.M. Liu contributed to sample processing, and data acquisition and interpretation. Y. Chen recruited and obtained consent from the participants, and contributed to sample processing. L. Miyashita contributed to the study design and data analysis. W.H. Tam and N.A. Ngai facilitated the study design. J. Grigg contributed to study concept and supervised the study. T.F. Leung secured funding and supervised the study. All authors contributed to writing the final manuscript. All authors read and approved the final manuscript.

Data sharing statement: Study data are available to peer reviewers, and anonymised individual data are available on request to recognised academic institutions, health service organisations or commercial research organisations with experience in medical research.

Conflict of interest: N.M. Liu has nothing to disclose. Y. Chen has nothing to disclose. L. Miyashita has nothing to disclose. W.H. Tam has nothing to disclose. N.A. Ngai has nothing to disclose. J. Grigg reports personal fees from Vifor Pharma, AstraZeneca and GSK, outside the submitted work. T.F. Leung has nothing to disclose.

Support statement: This study was funded by a Hong Kong Institute of Allergy research grant. 
References

1 Pedersen M, Giorgis-Allemand L, Bernard C, et al. Ambient air pollution and low birthweight: a European cohort study (ESCAPE). Lancet Respir Med 2013; 1: 695-704.

2 Pereira G, Belanger K, Ebisu K, et al. Fine particulate matter and risk of preterm birth in Connecticut in 20002006: a longitudinal study. Am J Epidemiol 2014; 179: 67-74.

3 Hiraiwa K, van Eeden SF. Contribution of lung macrophages to the inflammatory responses induced by exposure to air pollutants. Mediators Inflamm 2013; 2013: 619523.

4 Campagnolo L, Massimiani M, Vecchione L, et al. Silver nanoparticles inhaled during pregnancy reach and affect the placenta and the foetus. Nanotoxicology 2017; 11: 687-698.

5 Yue H, Ji X, Zhang, Y, et al. Gestational exposure to PM(2.5) impairs vascularization of the placenta. Sci Total Environ 2019; 665: 153-161.

6 Liu NM, Miyashita L, Maher BA, et al. Evidence for the presence of air pollution nanoparticles in placental tissue cells. Sci Total Environ 2021; 751: 142235.

7 Shi Y, $\mathrm{Ng}$ E. Fine-scale spatial variability of pedestrian-level particulate matters in compact urban commercial districts in Hong Kong. Int J Environ Res Public Health 2017; 14: 1008.

8 Wright AK, Rao S, Range S, et al. Pivotal advance: expansion of small sputum macrophages in CF: failure to express MARCO and mannose receptors. J Leukoc Biol 2009; 86: 479-489.

9 Kulkarni N, Pierse N, Rushton L, et al. Carbon in airway macrophages and lung function in children. $N$ Engl J Med 2006; 355: 21-30.

10 Liu NM, Grigg J. Diesel, children and respiratory disease. BMJ Paediatr Open 2018; 2: e000210.

11 Liu N, Miyashita L, Grigg J. Reduced uptake of inhaled carbon in airway macrophages from children with cystic fibrosis. Eur Respir J 2018; 52: Suppl. 62, PA3413.

12 Nwokoro C, Ewin C, Harrison C, et al. Cycling to work in London and inhaled dose of black carbon. Eur Respir J 2012; 40: 1091-1097.

13 Bové $\mathrm{H}$, Bongaerts $\mathrm{E}$, Slenders $\mathrm{E}$, et al. Ambient black carbon particles reach the fetal side of human placenta. Nat Commun 2019; 10: 3866.

14 Gordon SB, Bruce NG, Grigg J, et al. Respiratory risks from household air pollution in low and middle income countries. Lancet Respir Med 2014; 2: 823-860.

15 Whitehouse AL, Miyashita L, Liu NM, et al. Use of cleaner-burning biomass stoves and airway macrophage black carbon in Malawian women. Sci Total Environ 2018; 635: 405-411. 